\title{
STUDY OF SERUM TESTOSTERONE IN DIABETES MELLITUS
}

\author{
Rajendra Prasad Kathula1, Chakrapani Alavala²
}

${ }^{1}$ Associate Professor, Department of Surgery, GMC, Nizamabad.

${ }^{2}$ Associate Professor, Department of Surgery, GMC, Nizamabad.

\begin{abstract}
\section{BACKGROUND}

Diabetes Mellitus is not a disease, but can be considered as a metabolic syndrome in which not only the sugar metabolism is impaired, but also is said to have profound effects or influence on other metabolic disorders. Almost, all the metabolic pathways will be affected in this dreadful disease. It's a slow poison, which starts showing its effects as the time progresses. One of the commonest complaint seen in the diabetes patients is the loss of libido or derangement in the sexual physiology. The most common complaints include the erectile dysfunction and mood elevations. The patients also complain of stressfulness. These symptoms point out towards a common source i.e. decrease in the testosterone levels. A sincere effort has been put in this study to understand the relations of total serum testosterone seen in diabetes mellitus patients. This may help the physicians, operating surgeons, and also anaesthetists to understand the plethora of metabolic disturbances seen in the diabetes mellitus and take necessary steps to correct such conditions and also take necessary preventive members that may result in catastrophe.
\end{abstract}

\section{METHODS}

This study is a cross-sectional study done in Government Medical College, Nizamabad. One hundred known diabetic patients who attended the Department of Surgery, Government Medical College, Nizamabad, were identified. The fasting levels of postprandial level and HbA1c were detected. The total testosterone level was identified. The incidence of low testosterone $(<300 \mathrm{ng} / \mathrm{dL}) \mathrm{was}$ checked. The different levels of glucose (Fasting, postprandial) and HbA1c was compared to the amount of serum total testosterone. Finally, the time since the diabetes was known to the patients were correlated to the levels of testosterone.

\section{RESULT}

In the present study, the incidence of the low total testosterone was found to be in 39 percent of the diabetics. In the present study, there is a positive correlation between the total testosterone levels and the number of years that have passed since the patient is known to be diabetic. In the present study, there was a positive correlation found between the serum total testosterone levels with the mean fasting glucose levels, mean postprandial, and mean HbA1c levels.

\section{CONCLUSION}

This study is intended to help the surgeons, physicians, and the anaesthetists in managing the patients with diabetes mellitus in a better way. Especially, pre and postsurgical patients in whom the stress levels are enormous. The testosterone also plays a role in controlling the stress. The testosterone supplementation therapy can be considered in these patients. The study has a lot of scope in the future. A gene has been identified to cause both obesity and diabetes and also lower the serum testosterone. So, the present study forms a base for further studies at a molecular level in understanding the disease better and also managing the patients better.

\section{KEYWORDS}

Total Serum Testosterone, Diabetes Mellitus, Relations, Testes, Metabolic.

HOW TO CITE THIS ARTICLE: Kathula RP, Alavala C. Study of serum testosterone in diabetes mellitus. J. Evolution Med. Dent. Sci. 2016;5(54):3616-3618, DOI: 10.14260/jemds/2016/833

\section{INTRODUCTION}

Sexual differentiation and the hormonal changes that accompany puberty along with the other secondary sexual characteristics development is the responsibility of the sexual glands. The most important hormone that brings about this act is the testosterone. The testosterone regulation is controlled by the so called master gland of the body-the pituitary gland. The LH and FSH released by the master gland regulate the testosterone secretion and also its release. In turn, this during embryonic development, testosterone and

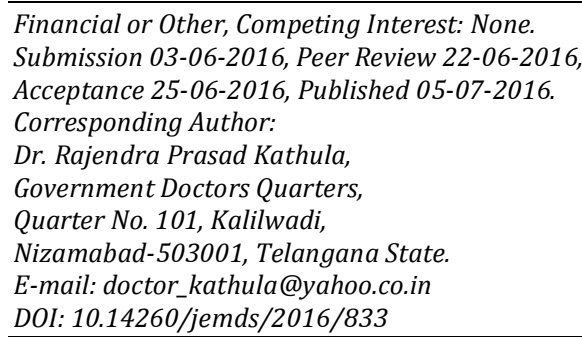

dihydrotestosterone, this testosterone helps the testes to descend and also help in the suppression of the female development. During puberty, testosterone promotes body growth and the development of secondary sexual characteristics like the development of the pubic hair and also in the mail patterns of the hair development and other sexual characters. Then, in adult, testosterone also called in layman language as the male hormone is necessary for spermatogenesis and stimulation of libido and normal sexual function in physiological limits.

Mutations in PC1 gene on locus 5q15-21 AR is known to cause obesity and diabetes mellitus. Two-thirds of all cases occurring in low to middle income countries. ${ }^{1}$ Asians develop diabetes at a younger age, at lower degrees of obesity and at much higher rates given the same amount of weight gain compared with Western populations. ${ }^{2}$ The prevalence of type 2 diabetes is high in Jordan and more than half of the patients with diabetes have unsatisfactory metabolic control. ${ }^{3}$ 
Diabetes mellitus is not a disease, but can be considered as a metabolic syndrome in which not only the sugar metabolism is impaired, but also is said to have profound effects or influence on other metabolic disorders. Almost, all the metabolic pathways will be affected in this dreadful disease. It's a slow poison, which starts showing its effects as the time progresses. One of the commonest complaints seen in the diabetes patients is the loss of libido or derangement in the sexual physiology. The most common complaints include the erectile dysfunction and mood elevations. The patients also complain of stressfulness. These symptoms point out towards a common source i.e. decrease in the testosterone levels.

$95 \%$ of circulating testosterone in males is derived from testicular secretion. The normal range is between $3 \mathrm{mg} / \mathrm{dL}$ to $10 \mathrm{mg} / \mathrm{dL}$ around 5 percent of the total testosterone is directly secreted by the adrenal and the peripheral conversion of androstenedione to testosterone collectively account for another 5 percent of testosterone. Circulating testosterone is bound to two plasma proteins: sex hormone-binding globulin and albumin. Sex hormone-binding globulin binds testosterone with much greater affinity than albumin. Only 5 to 30 percent of testosterone is unbound. The unbound form of testosterone is biologically active; however, albumin-bound hormone dissociates readily in the capillaries and may be bioavailable. Sex hormone-binding globulin concentrations are decreased by androgens (Male Sex Hormones), obesity, insulin, and nephrotic syndrome. Conversely, oestrogen administration, hyperthyroidism, many chronic inflammatory illnesses, and ageing are associated with high SHBG concentrations. Testosterone is metabolized predominantly in the liver, although some degradation occurs in peripheral tissues particularly the prostate and the skin. In the liver, testosterone is converted by a series of enzymatic steps into androsterone, etiocholanolone, DHT, and 3-androstanediol. These compounds undergo glucuronidation or sulfation before being excreted by the kidneys.

In liver diseases, the globulin-bound testosterone is decreased as the albumin and majority of the globulin is produced by the hepatocytes. This may be a fact to why the liver failure patients develop gynaecomastia. The association between low serum testosterone (LST) and DM has recently received substantial attention. 4,5 Studies have reported that men with type 2 DM (T2DM) have a high prevalence of LST.6,7,8 Further, reduced total testosterone (TT) levels have been associated with insulin resistance and subsequent risk for developing T2DM.9,10

Total testosterone includes both unbound and proteinbound testosterone and is measured by radioimmunoassays or immunometric assays. A single random sample provides a good approximation of the average testosterone concentration with the realization that testosterone levels fluctuate in response to pulsatile $\mathrm{LH}$. Testosterone is generally lower in the late afternoon and is reduced by acute illness. The testosterone concentration in healthy young men ranges from 300 to 1000 $\mathrm{ng} / \mathrm{dL}$ in most laboratories. Alterations in SHBG levels due to ageing, obesity, some types of medications, chronic illness, or on a congenital basis can affect total testosterone levels.

The main symptoms of LST are reduced libido/erectile dysfunction, reduced muscle mass and strength, increased adiposity, osteoporosis/low bone mass, depressed mood, fatigue, low energy, and impaired quality of life.11,12 A sincere effort has been put in this study to understand the relations of total serum testosterone seen in diabetes mellitus patients. This may help the physicians, operating surgeons, and also anaesthetists to understand the plethora of metabolic disturbances seen in the diabetes mellitus and take necessary steps to correct such conditions and also take necessary preventive members that may result in catastrophe.

\section{AIMS AND OBJECTIVES}

1. To measure the total serum testosterone.

2. To measure the fasting glucose, postprandial glucose, and HbA1c levels.

3. To find out the incidence of finding low total serum testosterone in diabetes mellitus patients.

4. To correlate the time since the diabetes was discovered and the levels of testosterone.

5. To correlate the levels of testosterone with the fasting glucose levels, postprandial glucose levels, and HbA1c levels.

\section{MATERIALS AND METHODS}

- This study is a cross-sectional study done in Government Medical College, Nizamabad.

- This is a double blinded selective randomisation study. One hundred known diabetic patients who attended the Department of Surgery, Government Medical College, Nizamabad, were identified.

- $\quad$ The fasting levels, postprandial level, and HbA1c were detected.

- The total testosterone level was identified.

- The incidence of low testosterone $(<300 \mathrm{ng} / \mathrm{dL})$ was checked.

- $\quad$ The different levels of glucose (Fasting, postprandial) and HbA1c was compared to the amount of serum total testosterone.

- Finally, the time since the diabetes was known to the patients were correlated to the levels of testosterone.

\section{Inclusion Criteria}

1. Patients aged between $40-50$ years were included in the study to minimize the age-related bias.

2. Patients BMI was calculated and whose BMI were normal plus or minus 2 S.D were included in the study (Because obesity is a factor known to cause testosterone deficiency).

\section{Exclusion Criteria}

1. Patients undergoing testosterone replacement therapy were discarded.

2. Patients with secondary causes of hypogonadism were discarded.

3. Patients with other congenital abnormalities (Metabolic syndromes) were discarded.

\section{RESULTS}

\begin{tabular}{|c|c|}
\hline $\begin{array}{c}\text { Serum Total } \\
\text { Testosterone Levels }\end{array}$ & $\begin{array}{c}\text { Frequency of } \\
\text { Patients }\end{array}$ \\
\hline$<300 \mathrm{ng} / \mathrm{dL}$ & 39 \\
\hline $300-1000 \mathrm{ng} / \mathrm{dL}$ & 61 \\
\hline$>1000 \mathrm{ng} / \mathrm{dL}$ & $\mathrm{NIL}$ \\
\hline Table 1: Serum Total Testosterone Levels \\
\hline
\end{tabular}




\begin{tabular}{|c|c|}
\hline $\begin{array}{c}\text { Serum Total } \\
\text { Testosterone Levels }\end{array}$ & $\begin{array}{c}\text { Number of Mean Years of } \\
\text { Known Diabetes Mellitus }\end{array}$ \\
\hline$<300 \mathrm{ng} / \mathrm{dL}$ & 8.46 years \\
\hline $300-1000 \mathrm{ng} / \mathrm{dL}$ & 5.2 years \\
\hline$>1000 \mathrm{ng} / \mathrm{dL}$ & NIL \\
\hline \multicolumn{2}{|c|}{$\begin{array}{c}\text { Table 2: Correlation of Total Testosterone Levels } \\
\text { with Mean Known Years of Diabetes Mellitus }\end{array}$} \\
\hline
\end{tabular}

\begin{tabular}{|c|c|c|c|}
\hline $\begin{array}{c}\text { Serum Total } \\
\text { Testosterone } \\
\text { Levels }\end{array}$ & $\begin{array}{c}\text { Mean } \\
\text { Fasting } \\
\text { Level }\end{array}$ & $\begin{array}{c}\text { Mean } \\
\text { Postprandial } \\
\text { Glucose Level }\end{array}$ & $\begin{array}{c}\text { Mean } \\
\text { HbA1c }\end{array}$ \\
\hline$<300 \mathrm{ng} / \mathrm{dL}$ & $\begin{array}{c}188.8 \\
\mathrm{mg} / \mathrm{dL}\end{array}$ & $245.2 \mathrm{mg} / \mathrm{dL}$ & 8.9 \\
\hline $300-1000 \mathrm{ng} / \mathrm{dL}$ & $\begin{array}{c}148.2 \\
\mathrm{mg} / \mathrm{dL}\end{array}$ & $192.6 \mathrm{mg} / \mathrm{dL}$ & 7.8 \\
\hline$>1000 \mathrm{ng} / \mathrm{dL}$ & -- & -- & -- \\
\hline \multicolumn{3}{|c|}{ Table 3: Showing the Relation of Serum Total } \\
Testosterone Levels with the Mean Fasting Glucose \\
Levels, Mean Postprandial, and Mean HbA1c Levels \\
\hline
\end{tabular}

Fig. 1: Showing the inter-relationship between the serum total testosterone levels with the mean fasting glucose levels, mean postprandial, and mean HbA1c levels.

\section{DISCUSSION}

In the present study, the incidence of the low total testosterone was found to be in 39 percent of the diabetics.

In a study conducted by Ayman A. Al Hayek et al ${ }^{13} 36.5 \%$ of the study population was reported to have low total testosterone. This might be due to the fact that the study population is different and the different food culture and environmental factors may be determined to be the cause.

The study conducted by Afaf Khairey Esmaeel ${ }^{14}$ in Iraq did not show any significant difference in the testosterone levels in the diabetic population. This result may be due to the fact that the study conducted by Afaf Khairey Esmaeel ${ }^{14}$ was in ten subjects. Considering the mighty proportions of the disease, ten subjects may be a little less to find the significant relations. In the present study, there is a positive correlation between the total testosterone levels and the number of years that have passed since the patient is known to be diabetic.

Similar observations were made in the study conducted by Ayman A. Al Hayek et al. ${ }^{13}$ So, the present study is in agreement with the other study.

In the present study, there was a positive correlation found between the serum total testosterone levels with the mean fasting glucose levels, mean postprandial, and mean $\mathrm{HbA1c}$ levels. Similar observations were made in the study conducted by Ayman $\mathrm{A}$. Al Hayek et al ${ }^{13}$ The correlation was based upon the two-tailed method of significance. $(<0.05)$ The statistical analysis was found by SPSS software 2015.

\section{CONCLUSION}

The incidence of the low testosterone is seen in a significant amount of diabetic population. There is a positive correlation between the blood glucose levels, HbA1c, and testosterone levels. This study is intended to help the surgeons, physicians, and the anaesthetists in managing the patients with diabetes mellitus in a better way. Especially, pre and postsurgical patients in whom the stress levels are enormous, the testosterone also plays a role in controlling the stress. The testosterone supplementation therapy can be considered in these patients. The study has a lot of scope in the future. A gene has been identified to cause both obesity and diabetes and also lower the serum testosterone. So, the present study forms a base for further studies at a molecular level in understanding the disease better and also managing the patients better.

\section{REFERENCES}

1. International diabetes federation. IDF diabetes atlas. Epidemiology and morbidity. International Diabetes Federation. Available from: http://www.idf.org/

2. Chan JC, Malik V, Jia W, et al. Diabetes in Asia: epidemiology, risk factors, and pathophysiology. JAMA 2009;301(20):2129-40.

3. Ajlouni K, Khader YS, Batieha A, et al. An increase in prevalence of diabetes mellitus in Jordan over 10 years. J Diabetes Complications 2008;22(5):317-24.

4. George JT, Veldhuis JD, Tena-Sempere M, et al. Exploring the pathophysiology of hypogonadism in men with type 2 diabetes: Kisspeptin-10 stimulates serum testosterone and LH secretion in men with type 2 diabetes and mild biochemical hypogonadism. Clin Endocrinol (Oxf) 2013;79(1):100-4.

5. Ghazi S, Zohdy W, Elkhiat Y, et al. Serum testosterone levels in diabetic men with and without erectile dysfunction. Andrologia 2012;44(6):373-80.

6. Kohler TS, Kim J, Feia K, et al. Prevalence of androgen deficiency in men with erectile dysfunction. Urology 2008;71(4):693-7.

7. Rezvani MR, Saadatjou SA, Sorouri S, et al. Comparison of serum free testosterone, luteinizing hormone and follicle stimulating hormone levels in diabetics and non-diabetics men - a case-control study. J Res Health Sci 2012;12(2):98-100.

8. Tamler R, Deveney T. Hypogonadism, erectile dysfunction, and type 2 diabetes mellitus: what the clinician needs to know. Postgrad Med 2010;122(6):16575.

9. Grossmann M, Thomas MC, Panagiotopoulos S, et al. Low testosterone levels are common and associated with insulin resistance in men with diabetes. J Clin Endocrinol Metab 2008;93(5):1834-40.

10. Soriguer F, Rubio-Martin E, Fernandez D, et al. Testosterone, SHBG and risk of type 2 diabetes in the second evaluation of the Pizarra cohort study. Eur J Clin Invest 2012;42(1):79-85.

11. Dandona P, Rosenberg MT. A practical guide to male hypogonadism in the primary care setting. Int J Clin Pract 2010;64(6):682-96.

12. Zhang XW, Liu ZH, Hu XW, et al. Androgen replacement therapy improves psychological distress and healthrelated quality of life in late onset hypogonadism patients in Chinese population. Chin Med J (Engl) 2012;125(21):3806-10.

13. Al Hayek AA, Khader YS, Jafal S, et al. Prevalence of low testosterone levels in men with type 2 diabetes mellitus: a cross-sectional study. J Family Community Med 2013;20(3):179-86. doi: 10.4103/2230-8229.122006.

14. Esmaeel AK. Relationships between diabetes mellitus type 2 and male testosterone level. Journal of Babylon University/Pure and Applied Sciences 2013;21(1). 